\title{
ESCOLA PÚBLICA EM MINAS GERAIS: GÊNESE DO GRUPO ESCOLAR ILDEFONSO MASCARENHAS DA SILVA (ANOS 1940-50) ${ }^{1}$
}

\author{
Betânia de Oliveira Laterza Ribeiro ${ }^{2}$ \\ Valéria Aparecida de Lima $^{3}$ \\ Armindo Quillici Neto ${ }^{4}$
}

\section{RESUMO}

O primeiro grupo escolar de Ituiutaba (MG) começou a funcionar em 1910; o segundo, em 1947. Como esse meio-tempo foi de expansão nacional da educação pública, a diferença de 37 anos suscita vários questionamentos. Por exemplo: por que esse município formalizou o primeiro grupo escolar em 1908 - quando sua economia era inexpressiva - e o segundo em 1947 - quando sua economia se projetava no estado e no país? Este estudo problematiza historicamente a criação do grupo escolar Ildefonso Mascarenhas nessa relação entre educação (precária) e economia (ascendente), sem se furtar aos aspectos políticos e sociais que permeiam tal relação. As fontes dessa problematização abrangem dados demográfico-estatísticos, imprensa escrita, relatos orais e fotografias, analisados interpretativamente. Dentre outros achados, os resultados sugerem que a criação da escola resultou menos da ação de políticos, e mais do esforço de sujeitos ligados diretamente à educação; e que o papel do Estado se restringiu mais à formalização legal da escola do que a seu funcionamento cotidiano. Ao discutir essas questões, este estudo buscou ampliar a escrita de uma história-problema da educação no país, sobretudo da tentativa de massificar a alfabetização pela difusão de um modelo escolar como política pública.

Palavras-chave: educação, economia, modelo escolar, alfabetização.

\section{PUBLIC SCHOOL IN MINAS GERAIS STATE: GENESIS OF GRUPO ESCOLAR ILDEFONSO MASCARENHAS DA SILVA (1940s AND 1950s)}

\begin{abstract}
The first state public school of Ituiutaba, Minas Gerais state, started to operate in 1910; the second one 37 years later. As in the meantime a national public education took place, such time gap raises some questions. For example, how such municipality managed to constitute its first public school in 1908 - when its economy was inexpressive - and the second one in 1947 - when its economy was ascending. This study focuses on this question in a historical approach. For that, it considers the creation of Ildefonso Mascarenhas public school by taking into account the relationship between education and economy as well as political and social aspects which permeate it. It relies on sources such as demographic, statistical data, press, oral accounts, and photographs, which are analyzed on an interpretive basis. Among other, its findings suggest that the creation of the school resulted less from political efforts than efforts by individuals which had strong bonds with education per se; that state's role was more restrained to the school legal formalization than to its practical functioning. In discussing these matters, this study has sought to enlarge the history of education in Brazil, especially the attempt at promoting mass literacy by spreading a schooling model as a public policy.
\end{abstract}

Keywords: education, economy, schooling model, mass literacy. 


\section{Introdução}

A criação e o funcionamento de escolas públicas em Ituiutaba (MG) remetem a 1910, ano de inauguração do primeiro grupo escolar - o João Pinheiro; ${ }^{5}$ enquanto o segundo - o Grupo Escolar Professor Ildefonso Mascarenhas da Silva - começou a funcionar só em 1947. Essa lacuna de 37 anos supera até o lapso de tempo entre a criação do primeiro grupo escolar ituiutabano e o surgimento mesmo do grupo escolar, em 1893, na cidade de São Paulo.

Tal lacuna temporal sugere que a expansão dos grupos escolares ${ }^{6}$ no município foi tímida e precária, mesmo preocupasse o governo republicano e mesmo que o surgimento de quatro escolas particulares nesse intervalo possa ser tomado como medida da demanda educacional formal e da ação da educação privada no ensino primário. Também permite supor que houve pouco investimento público na escolarização num município cujo desenvolvimento urbano e econômico se destacou no estado e no país, sobretudo na década de 1950, quando a expansão escolar local se intensificou. Até 1930, a economia de Ituiutaba girava em torno da atividade agropecuária; em 1935, impôs-se o ciclo do garimpo de diamante no rio Tejuco; a partir de 1950, o cultivo do arroz predominou como atividade econômica — a força rizicultora do município era tal que Ituiutaba ficou conhecida como "celeiro do Triângulo", "capital do arroz".

Eis, então, o campo de problematização deste texto: certa contradição entre desenvolvimento econômico ascendente e sua desarticulação com o desenvolvimento da escola pública. Essa relação entre economia e educação é relevante porque a população quase triplicou em virtude da prosperidade que o crescimento econômico suscitava, sem que o município oferecesse um aparato de ensino público que acompanhasse tal aumento populacional; isto é, sem que houvesse um número maior de grupos escolares, modelo de escola que se impôs como ícone da educação republicana e instrumento para acabar com os índices elevados de analfabetismo.

\section{O grupo escolar}

No século XIX, havia uma multiplicidade de modelos de escola (e formas de escolarização) funcionando em espaços improvisados ou alugados e cujos professores eram reconhecidos ou nomeados por órgãos governamentais. Para reunir tais escolas, surgiram os grupos escolares, que as agrupavam segundo a proximidade. Saviani (2004) esclarece que estes constituíram um fenômeno tipicamente urbano, pois no meio rural as escolas isoladas predominaram por muito mais tempo. (Isoladas porque eram desvinculadas institucionalmente de qualquer tentativa do poder público de organizar um sistema educacional.) Em Minas Gerais, a crítica a elas era intensa, sobretudo à desorganização e à dificuldade de controlá-las — segundo a visão do governo.

Para esse quadro educacional convergiu a instituição do grupo escolar, que apresentou um novo modelo de organização escolar ao novo modelo de organização político-administrativa que a proclamação da República impôs. Tal modelo reunia características centrais da escola graduada do fim do século XIX, comum em países europeus e nos Estados Unidos como meio de educar a população maciçamente, sobretudo a urbana. (Como escola urbana, o grupo escolar foi instrumento de seleção, pois em seus primórdios formou essencialmente elites; talvez porque a educação das massas tenha preocupado os governos só nos anos 1920, quando foi objeto de reforma educacional, por exemplo, no estado de São Paulo.)

Afirmar que os grupos escolares eram escolas graduadas significa dizer que tinham turmas seriadas, as quais, em essência, classificavam os alunos em grupos supostamente 
homogêneos que levam à formação de classes (SOUZA, 2004). O grupo escolar apresentava outras características:

[...] adoção do ensino simultâneo, a racionalização curricular, controle e distribuição ordenada dos conteúdos e do tempo (graduação dos programas e estabelecimento de horários), a introdução de um sistema de avaliação, a divisão do trabalho docente e um edifício escolar compreendendo várias salas de aula e vários professores. O modelo colocava em correspondência a distribuição do espaço com os elementos da racionalização pedagógica - em cada sala de aula uma classe referente a uma série; para cada classe, um professor. (SOUZA, 2004, p. 114).

Fornecido em quatro anos, o ensino primário seguia um programa disciplinar que visavam proporcionar educação integral - isto é, moral, intelectual e física. O método de ensino era o intuitivo, oriundo da Alemanha e difundido pela Europa na segunda metade do século XIX; trabalhar com esse método significava prever a intuição como base do conhecimento; ou seja, compreender que "[...] a aquisição dos conhecimentos decorria dos sentidos e da observação" (SOUZA, 1998, p. 26); que o ensino devia ir do particular para o geral, do concreto para o abstrato. Para estudar nos grupos escolares, o aluno deveria ter idade entre 7 e 12 anos. A legislação vigente determinava que, ao se matricular, a criança devia apresentar um atestado de boa saúde - de que não tinha doença contagiosa - e o certificado de vacinação com resultado favorável. Assiduidade, asseio, ordem e obediência entre os discentes davam o tom da rigidez da disciplina. O calendário letivo se impôs como forma de controlar o tempo escolar. Exames finais, exposições, datas cívicas e festas de encerramento de ano letivo compunham práticas ritualizadas e simbólicas.

Essas inovações constituíam novos dispositivos de racionalização administrativa e pedagógica que permitem ver o grupo escolar hoje como projeto cultural favorável não só à nação, mas também ao desenvolvimento do capitalismo e de processos que este desencadeou - urbanização e industrialização. No dizer de Faria Filho (1996, p. 39), a defesa da instrução pública - a instituição dos grupos escolares — pode ser vista como tentativa de integrar o "[...] povo à nação e ao mercado de trabalho assalariado [...]", estimulado por fatos como a proclamação da República e a abolição; dentre outros, esses acontecimentos davam pistas de

[...] um momento crucial de produção da necessidade de re-fundar a escola pública, uma vez que aquela que existia era identificada como atrasada e desorganizada. Tal escola, assim representada, não poderia levar avante tarefas tão complexas como aquelas projetadas para a mesma.

Assim, o controle, a racionalização e a padronização que o grupo escolar oferecia convergiam para a projeção do trabalho assalariado como modo de produção que demandava cada vez mais pessoas aptas a ler, escrever e calcular.

Se assim o for, pode-se dizer que esse modelo de escola continha uma ideia preliminar de educar maciçamente, pois subjacente à ideia de grupo escolar havia o propósito republicano - concebido por intelectuais-políticos e políticos-intelectuais — de disseminar a instrução escolar em meio à população como forma de possibilitar o desenvolvimento nacional. Nesse sentido, diz Araujo (2006), o grupo escolar organizava o ensino elementar de forma mais racionalizada e padronizada para absorver um número elevado de crianças; ou seja, para escolarizar em massa, para universalizar a escolarização popular. "Ao implantá-lo políticos, intelectuais e educadores paulistas almejavam modernizar a educação e elevar o país ao patamar dos países mais desenvolvidos." (ARAUJO, 2006, p. 35). 
Pode-se falar em educação em massa nos anos 50 porque, também, o analfabetismo era maciço país afora (TAB. 1). O recenseamento de 1950 aponta a média nacional de $51,75 \%$ de analfabetos (MOURA SOBRINHO; INACIO FILHO, 2002, p. 94). Se uma média tal sugere que em 50 anos as campanhas de alfabetização tiveram impacto na redução da taxa de analfabetismo caso se considere a taxa de $80 \%$ na virada do século; então tal impacto merece relativização caso se considere que Alagoas em 1950 apresentava $76,55 \%$ de analfabetos. As taxas de outros estados nordestinos permitem cogitar que a República pouco fez para resolver o problema no Nordeste. Com base nesses dados, é plausível dizer que o financiamento da educação pública foi inadequado estruturalmente, pois não resultou numa população maciçamente alfabetizada.

Mesmo Minas, cuja projeção política e econômica se alinhava à de São Paulo, não alfabetizou em massa sua população na primeira metade do século (TAB. 2). Em 1950, um município como Ituiutaba apresentava $57,35 \%$ de analfabetismo: taxa superior ao de MG, do AM e do país proporcionalmente. Isso sugere que a política (a ação) educacional mineira replicava a ineficácia de estados menos proeminentes política e economicamente; também punha em xeque os ideais republicanos - e mineiros - de modernizar o país e fazê-lo progredir via educação pública para afirmar uma sociedade liberal e capitalista.

\section{TABELA 1}

Índice (\%) de analfabetismo no Brasil - recenseamento de 1950

\begin{tabular}{|c|c|c|c|c|c|c|c|c|c|c|c|}
\hline \multicolumn{2}{|c|}{ NORTE } & \multicolumn{2}{|c|}{ NORDESTE } & \multicolumn{2}{|c|}{ SUL } & \multicolumn{2}{|c|}{ SUDESTE } & \multicolumn{2}{|c|}{ CENTRO-OESTE } & \multicolumn{2}{|c|}{$\mathrm{DF}$} \\
\hline $\mathrm{AC}$ & 65,62 & $\mathrm{AL}$ & 76,55 & PR & 47,32 & MG & 56,19 & GO & 66,76 & $\begin{array}{l}\text { R. de } \\
\text { Janeiro }\end{array}$ & 15,04 \\
\hline AM & 57,15 & MA & 74,78 & $\mathrm{RS}$ & 37,78 & ES & 52,89 & MT & 43,73 & - & - \\
\hline AP & 55,92 & PI & 74,11 & $\mathrm{SC}$ & 35,89 & RJ & 44,03 & - & - & - & - \\
\hline $\begin{array}{l}\text { Rio } \\
\text { l }\end{array}$ & 55,50 & PA & 70,82 & - & - & SP & 34,70 & - & - & - & - \\
\hline Branco $^{1}$ & & & & & & & & & & & \\
\hline PA & 51,29 & $\mathrm{CE}$ & 68,82 & - & - & - & - & - & - & - & - \\
\hline Guaporé $^{2}$ & 50,08 & PE & 68,65 & - & - & - & - & - & - & - & - \\
\hline- & - & BA & 68,45 & - & - & - & - & - & - & - & - \\
\hline - & - & $\mathrm{RN}$ & 68,02 & - & - & - & - & - & - & - & - \\
\hline - & - & SE & 66,37 & - & - & - & - & - & - & - & - \\
\hline
\end{tabular}

Território Federal do Rio Branco era a denominação do atual estado de Roraima

${ }^{2}$ Território Federal do Guaporé era a denominação do atual estado de Rondônia

Fonte: MOURA SOBRINHO; INÁCIO FILHO, 2002, p. 94.

TABELA 2

Escolarização de pessoas com mais de 5 anos de idade - Ituiutaba, 1950

\begin{tabular}{|c|c|c|c|c|c|c|}
\hline \multirow{2}{*}{\multicolumn{2}{|c|}{ Discriminação }} & \multicolumn{3}{|c|}{ NÚMEROS ABSOLUTOS } & \multicolumn{2}{|c|}{$\%$ SOBRE O TOTAL } \\
\hline & & \multirow{2}{*}{$\begin{array}{r}\text { Total } \\
4.032\end{array}$} & \multirow{2}{*}{$\begin{array}{c}\text { Sabem ler, mas } \\
\text { não escrever } \\
3.115\end{array}$} & \multirow{2}{*}{$\begin{array}{c}\text { Não sabem ler } \\
\text { nem escrever } \\
917\end{array}$} & \multirow{2}{*}{$\begin{array}{c}\text { Sabem ler; mas } \\
\text { não escrever } \\
77,25\end{array}$} & \multirow{2}{*}{$\begin{array}{c}\text { Não sabem ler } \\
\text { nem escrever } \\
22,75\end{array}$} \\
\hline Quadro & Homens & & & & & \\
\hline urbano & Mulheres & 4.445 & 2.931 & 1.514 & 65,93 & 34,07 \\
\hline & Total & 8.477 & 6.046 & 2.431 & 71,32 & 28,68 \\
\hline Quadro & Homens & 18.300 & 7.116 & 11.184 & 38,88 & 61,12 \\
\hline rural & Mulheres & 16.312 & 5.218 & 11.094 & 31,98 & 68,02 \\
\hline & Total & 34.612 & 12.334 & 22.278 & 35,63 & 64,37 \\
\hline Em & Homens & 22.332 & 10.231 & 12.101 & 45,81 & 54,19 \\
\hline geral & Mulheres & 20.757 & 8.149 & 12.608 & 39,25 & 60,75 \\
\hline & Total & 43.089 & 18.380 & 24.609 & 42,65 & $\mathbf{5 7 , 3 5}$ \\
\hline
\end{tabular}

Fonte: RIBEIRO, 2010, com base no censo de 1950.

"Capital do arroz", "celeiro de analfabetos" 
Se as políticas públicas para a educação em Minas replicavam a ineficácia das políticas nacionais, então o município de Ituiutaba replicou a ineficácia da política estadual; igualmente, exemplificou a frouxidão dos elos entre projeção econômica e política e a escolarização, tal qual Minas Gerais a exemplificou em nível nacional. Economicamente, o município experimentou uma fase extrativista - com a mineração no rio Tejuco entre 1935 e 1945 — antes de focar na produção agropecuária, marcada pela instalação de uma máquina de beneficiar arroz e a abertura de uma fábrica de manteiga e óleo de algodão. Esses empreendimentos reafirmaram uma vocação à atividade agropecuária e incentivaram o desenvolvimento de lavouras de arroz — já existentes, mas em pequena escala - e de algodão - que passou a disputar espaço com o milho e o feijão. A produção de arroz delimitou o ciclo econômico tido como mais importante, a ponto de chamarem a cidade de "capital do arroz" nos anos 50. Para trabalhar nas lavouras, os produtores buscaram mão de obra em regiões mais pobres de Minas (Luz, Alto Paranaíba, Vale do Jequitinhonha e norte) e no Nordeste ${ }^{7}$ assim, até o fim da década de 1960, migrantes de lugares distintos, mas predominantemente do Rio Grande do Norte e da Paraíba, vieram compor a massa de analfabetos de $57 \%$ da população de Ituiutaba e região.

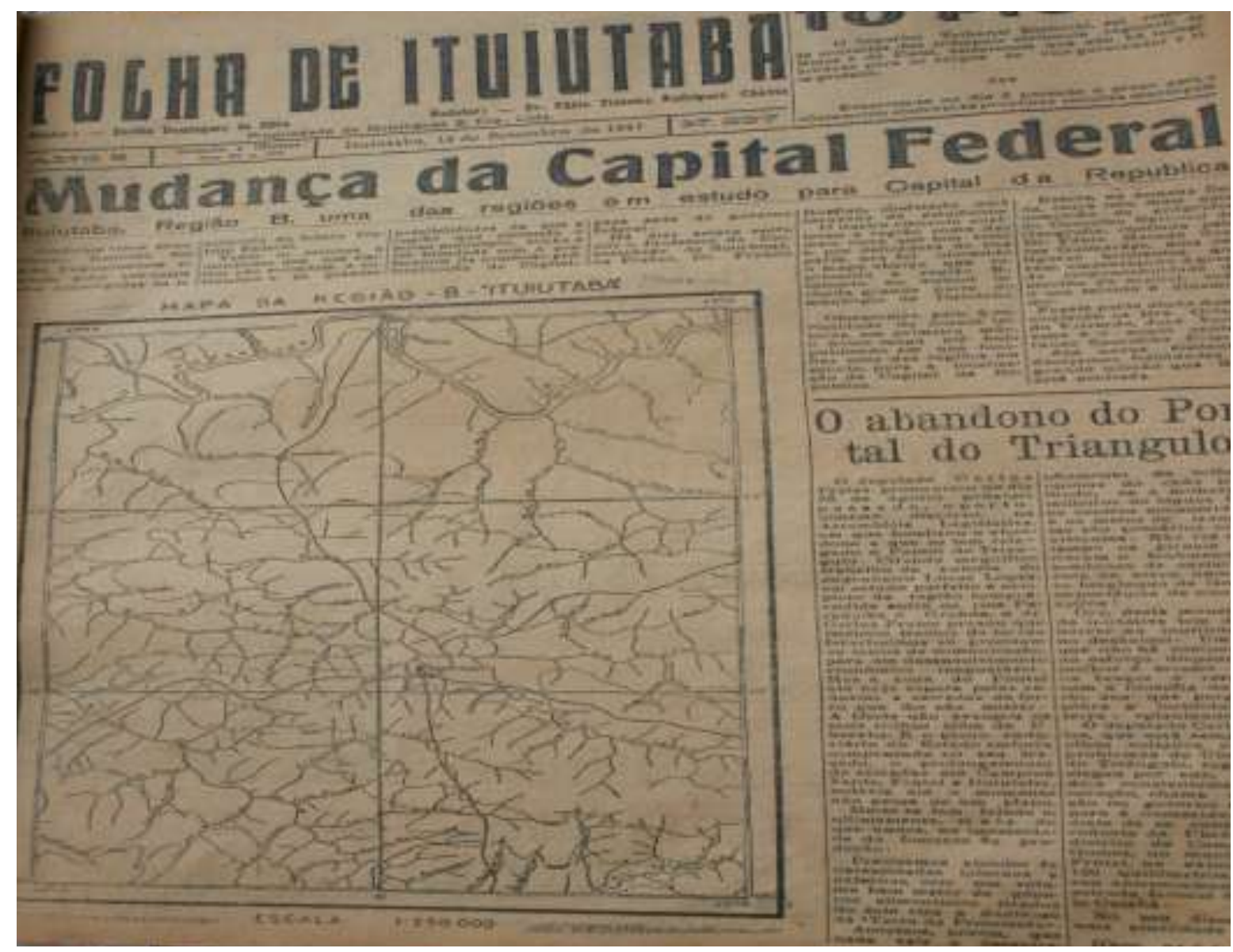

FIGURA 1 - Reprodução de página de jornal divulgando o mapa representativo da região B, que incluía grande parte do município de Ituiutaba ${ }^{8}$

Fonte: FOLHA DE ITUIUTABA, 1947, p. 1.

A projeção econômica regional do município o pôs na pauta de discussão do governo federal, que cogitou Ituiutaba como opção possível para ser a nova capital federal. A manchete "Mudança da Capital Federal" impressa em jornal dessa cidade em 14 de 
setembro de 1947 intitula a notícia referente à possibilidade da escolha (FIG. 1). Embora não concretizado, esse projeto sinalizou o desenvolvimento econômico do município nas décadas estudadas. Porém, o desenvolvimento educacional não acompanhava o econômico. Mesmo que o município tenha tido certa ascendência no governo estadual para demandar e obter — já em 1910 — a implementação de um grupo escolar, até 1947 o número de escolas públicas ficou restrito a um. Ao aumento populacional não equivaleu aumento na quantidade destas como houve noutras localidades mineiras. ${ }^{9}$

A carência de escola pública foi suprida pela escola privada, decisiva para alfabetização no município na primeira metade do século passado. Entre 1921 e 1930, surgiram o Colégio das Irmãs Belgas, o Instituto Propedêutico Ituiutaba e a Escola São José; no período 1930-40, destacou-se a escola privada confessional; no decênio de 30, foram criadas duas escolas laicas privadas: o Instituto Marden, instalado em 1933, e o Colégio Santa Teresa (confessional), fundado em 1939. Além dessas instituições, passou a funcionar, em 1948, o Ginásio São José, também confessional (QUADRO 1).

Essas escolas particulares e a quase inexistência de escolas públicas apontam uma educação seletiva, porque acessível à população que podia pagar; por outro lado, a população urbana cresceu sobremaneira, por causa da migração (vide Tabela 3), logo, é provável que a maior parte não pudesse arcar com os custos da escolarização privada.

\section{QUADRO 1}

Escolas urbanas de Ituiutaba - 1900-40

\begin{tabular}{|c|c|c|}
\hline PERÍODO & PÚBLICA & PARTICULAR \\
\hline $1901-10$ & $\begin{array}{l}\text { Grupo Escolar } \\
\text { João Pinheiro }\end{array}$ & $\begin{array}{l}\text { Escola do Professor Jose de Alencar; Escola do Professor Afonso José; } \\
\text { Colégio Santa Cruz; Externato/Colégio São Luiz; Colégio Santo Antônio }\end{array}$ \\
\hline $1911-20$ & - & Falta de dados impediu elencar as escolas desse período \\
\hline $1921-30$ & - & $\begin{array}{l}\text { Colégio das Irmãs Belgas; Instituto Propedêutico Ituiutaba; Escola São } \\
\text { José (popularmente Escola do Laurindo) }\end{array}$ \\
\hline $1931-40$ & - & $\begin{array}{l}\text { Instituto Marden; Colégio Menino Jesus de Praga; Colégio Santa Tereza; } \\
\text { Colégio São José }\end{array}$ \\
\hline
\end{tabular}

Fonte: MORAES, 2004, p. 55.

TABELA 3

População rural e urbana do município de Ituiutaba

\begin{tabular}{c|c|c|c|c|c}
\hline ANO & POPULAÇÃO RURAL & $\%$ & POPULAÇÃO URBANA & $\%$ & TOTAIS \\
\hline 1940 & 30.696 & $88 \%$ & 4.356 & $12 \%$ & $\mathbf{3 5 . 0 5 2}$ \\
1950 & 43.127 & $81 \%$ & 10.113 & $19 \%$ & $\mathbf{5 3 . 2 4 0}$ \\
1960 & 39.488 & $55 \%$ & 31.516 & $45 \%$ & $\mathbf{7 1 . 0 0 4}$ \\
1970 & 17.542 & $27 \%$ & 47.114 & $73 \%$ & $\mathbf{6 4 . 6 5 6}$ \\
\hline
\end{tabular}

Fonte: SOUZA, 2010.

Essa carência de escolas públicas no município converge para certas afirmações do governo federal: em parte, reafirmava as palavras do presidente Gaspar Dutra em mensagem dirigida ao Congresso em 1949: a “[...] educação primária [...] não mais poderá ser esquecida ou relegada [...]"; em parte, punha em xeque a afirmação de que "[...] a cooperação administrativa dos dois níveis de governo, — o federal e o estadual, foi posta à prova com tal sucesso pela experiência dos últimos anos, e frutificou tão amplamente [...]" (DUTRA, 1949, p. 110). Ora, a lacuna de 37 anos entre a criação do primeiro grupo escolar e do segundo deixa entrever não só esquecimento relativo à educação primária no município - seja pela União, seja pelo Estado —, mas também insucesso na empreitada conjunta entre governo brasileiro e governo mineiro. 
Essa situação se torna mais curiosa porque Ituiutaba era um município em ascensão econômica, logo é provável que escapasse ao problema das “[...] debilidades das finanças [...]" a que se refere Dutra; noutros termos, é provável que pudesse "[...] custear certos ideais de bem-estar público, inscritos [...]" em documentos constitucionais (DUTRA, 1949, p. 110). Se assim o for, então o discurso do presidente faz sentido na medida em que se refere a "[...] uma forma de empreendimento conjunto para melhor atacar o problema [da educação primária] [...]", que foi bem-sucedida segundo a experiência de anos anteriores (DUTRA, 1949, p. 110), por exemplo, 1947, ano em que foi criado o segundo grupo escolar de Ituiutaba.

\section{Gênese do segundo grupo escolar de Ituiutaba}

Criado pelo decreto 2.395, de 31 de janeiro de 1947, publicado no Diário Oficial de Minas Gerais em $1^{\circ}$ de fevereiro de 1947, o Grupo Escolar Professor Ildelfonso Mascarenhas da Silva foi instalado solenemente em 9 de março de 1947 (FIG. 1); à solenidade compareceram autoridades do município, docentes, convidados e um representante da Secretaria Estadual de Educação. À criação do grupo escolar subjazeu a articulação do então secretário Ildefonso Mascarenhas ${ }^{11}$ com seu oficial de gabinete Hélio Benício de Paiva. Ituiutabano, Paiva estabeleceu vínculos de amizade com Mascarenhas quando este foi professor daquele no curso de Direito: “[...] eu tinha sido aluno dele e, num concurso com vários concorrentes, eu tirei em primeiro lugar; [então] ele mandou me chamar também pra auxiliar no gabinete" (PAIVA, 2009, entrevista). O chamado foi feito mediante telegrama, cuja mensagem revela certo tom de pessoalidade (FIG. 2).

Resistente a princípio quanto a ir para a capital mineira — " $[$...] eu não queria ir pra Belo Horizonte [...]" —, Paiva foi convencido por "[...] muitas pessoas [...] de Ituiutaba [que] falou assim: 'Não! É uma ocasião que, talvez você possa servir e trazer alguma coisa pra Ituiutaba'. E de fato [...] eu consegui trazer pra Ituiutaba um grupo [escolar]" (PAIVA, 2009, entrevista).

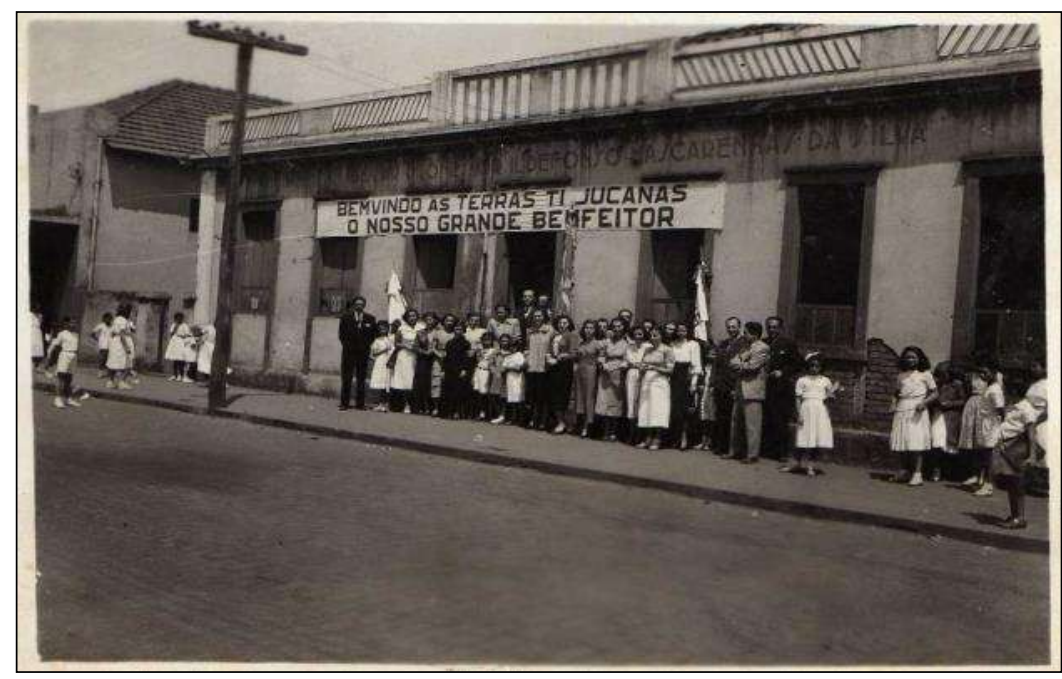

FIGURA 1 - Em 1947, o secretário de Educação Ildefonso Mascarenhas da Silva (sob o portal da porta de entrada) visitou a primeira instalação da escola que levou seu nome, situada em um prédio da rua 20, número 1.070 Fonte: acervo de Nagib Bitar 


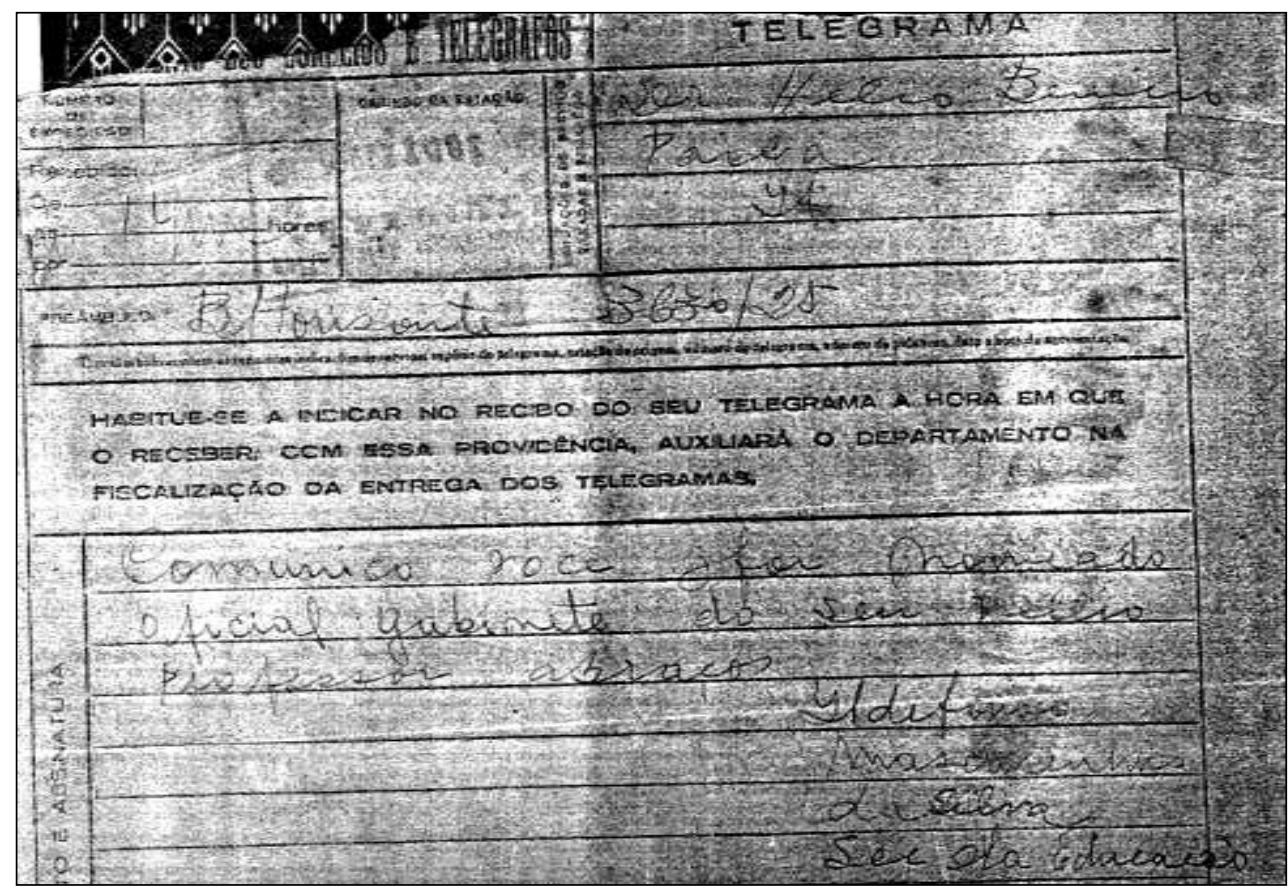

FIGURA 2 - Reprodução de telegrama confirmando a nomeação de Hélio Benício de Paiva para oficial de gabinete ${ }^{12}$

Fonte: acervo de PAIVA, 19[??].

Uma passagem do relato de uma ex-diretora do grupo escolar, Nagib Moukachar (2009, entrevista), ${ }^{13}$ revela certas circunstâncias da criação do grupo escolar Ildefonso Mascarenhas:

Foi o doutor Hélio [Benício] que selecionou [o corpo docente], e o doutor Omar [Diniz], que era prefeito, ajudou — [Omar] foi só contrário a uma professora, mas as outras ele aceitou direitinho. Não teve problema! Agora, não ficamos na prefeitura, nós já fomos nomeadas para o estado, entendeu? Nós não ficamos na prefeitura. O aluguel, no princípio, foi pago pela prefeitura, depois passou para o estado. Na escola velha, escola antiga, uma casa de portal grande, janelas grandes, entende? Era aquela antiga mesmo! 'Tava, assim, pra cair, e nós começamos com 400 e tantos alunos.

O relato deixa entrever três questões importantes relativas ao grupo escolar: a composição do corpo docente (FIG. 3), a responsabilidade pela administração e as condições materiais.

A seleção das professoras - como se pode ler — passou pelo crivo não só da Secretaria Estadual de Educação - "Todas as professoras para a escola Ildefonso Mascarenhas foram da minha indicação", disse Paiva (2009, entrevista) —, mas também da prefeitura. Essa forma de escolher sugere ausência de critérios mais pedagógicoprofissionais, pois ao cargo de professor se atribuía o peso dado ao de diretor e de oficial de gabinete: era cargo de confiança. Noutras palavras, é provável que a nomeação pressupusesse critérios políticos e de amizade, que podem ter levado uma professora a não ser contratada. A julgar pela formação de dona Nagib, cabe considerar que a origem social das professoras as situasse em famílias que podiam arcar com o ônus do curso Normal numa escola particular, porque compunham certa elite econômica da cidade e cujas tendências político-partidárias podiam se alinhar à situação ou tender à oposição; daí uma nomeação fundada, possivelmente, no favor. Essa consideração encontra respaldo em 
Fischer (2004, p. 1), que afirma que, "Em meados do século XX, com a expansão da escola pública no Brasil, amplia-se o número de instituições dedicadas à preparação do magistério, constituído basicamente de moças da classe média".

Do ponto de vista da administração da escola, o relato citado sugere que havia certa ambiguidade: se a prefeitura custeava o aluguel do prédio do grupo escolar e o prefeito escolhia as professoras, cabia ao estado administrá-lo e pagar as professoras.

Enfim, o relato aponta a precariedade da educação pública: a escola abriu suas portas a mais de 400 alunos mesmo que seu prédio estivesse prestes a cair; isso sugere que tentar escolarizar era mais importante do que as condições em que ocorreria a escolarização, talvez porque a quantidade de alfabetizados fosse mais importante do que a qualidade da alfabetização.

Logo foi preciso mudar a escola de lugar, pois o proprietário do prédio na rua 20 pediu o imóvel para construir um cinema - esclarece dona Nagib; a mudança era problemática porque significava paralisar a atividade do grupo escolar, que já estava "[...] fazendo formatura de $4^{\circ}$ ano" (MOUKACHAR, 2009, entrevista). A solução foi agrupar o Ildelfonso Mascarenhas com o Grupo Escolar João Pinheiro, também estadual: “[...] mandaram anexar provisoriamente ao João Pinheiro, e lá nós ficamos muitos anos. Sem a sede própria, nós ficamos - parece - 17 anos", conforme disse dona Nagib. Se o início da atividade escolar sugere precariedade na expansão da educação pública no município, o funcionamento de duas escolas num prédio parece não só reiterá-la, mas também apontar a urgência na escolarização, daí o improviso como política administrativo-escolar do estado mineiro.

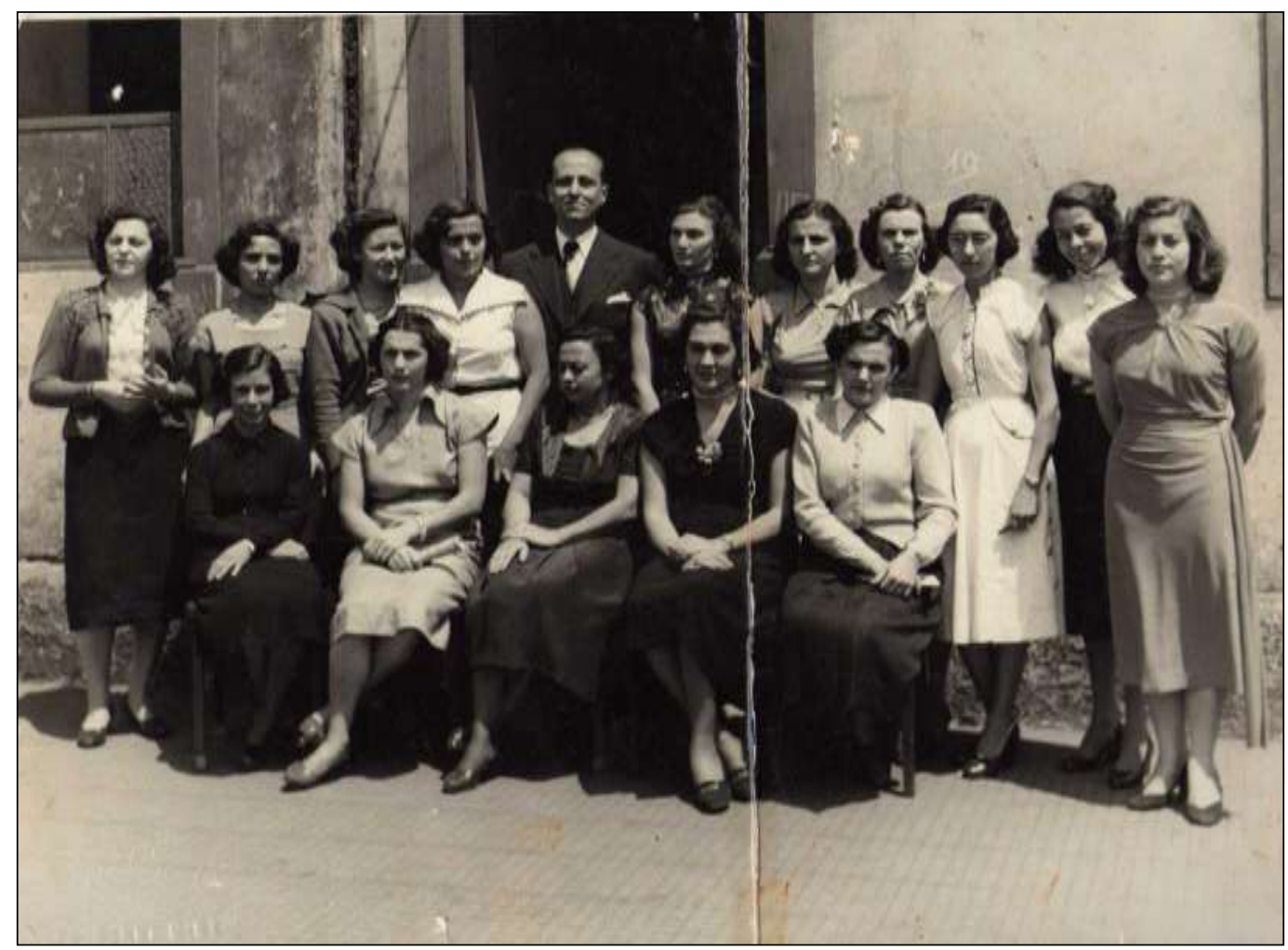

FIGURA 4 - Secretário de Educação do Estado professor Ildefonso Mascarenhas da Silva rodeado pelas professoras do grupo escolar na porta de entrada do prédio onde a escola iniciou suas atividades

Fonte: acervo de Nagib Bitar 


\begin{tabular}{|c|c|c|c|c|c|}
\hline \multicolumn{6}{|c|}{$\begin{array}{l}\text { Horário de aula do Grupo Escolar João Pinheiro e } \\
\text { Grupo Escolar Ildefonso Mascarenhas - } 1947\end{array}$} \\
\hline JOÃ & $\begin{array}{l}\text { PINHE } \\
\end{array}$ & & ILDEFOI & MASC & RENHAS \\
\hline ntrada & & Série & Entrada & Saída & Série \\
\hline $7 \mathrm{~h}$ & & $3^{\mathrm{a}}$ e $4^{\mathrm{a}}$ & - & - & - \\
\hline $10 \mathrm{~h} 30$ & $14 \mathrm{~h}$ & $1^{\mathrm{a}}$ e $2^{\mathrm{a}}$ & $14 \mathrm{~h}$ & $17 \mathrm{~h} 30$ & $1^{a}-4^{a}$ série \\
\hline
\end{tabular}

As escolas se igualavam administrativamente, mas o mesmo não pode ser dito no cotidiano escolar. Dona Nagib aponta o que a convivência de duas escolas no mesmo prédio, ainda que provisoriamente, poderia provocar:

Nós incomodávamos o João Pinheiro plenamente [...] Eu acredito que elas [as professoras] reclamavam, e a gente tinha que aceitar a reclamação. Era justa! Então era uma briga atrás da outra: a caixa d'água era aqui, a diretora do João Pinheiro não queria que fosse aqui, tinha que levar a caixa para lá...

As escolas não se misturavam, como sugere o horário da atividade em sala de aula: "[...] o João Pinheiro dava aulas das sete às dez e meia da manhã. Já pensa que horário ruim? [Às] dez e meia nós entrávamos, ficava lá, correndo páginas até às onze. A aula começava até às duas e meia da tarde (o outro turno do João Pinheiro), e nós éramos o terceiro turno. Nós saía quase seis [da tarde] da escola para dar três horas e meia de aula. Então, incomodamos muito o João Pinheiro”.

\section{Funcionamento do grupo escolar Ildefonso Mascarenhas}

O relato da ex-professora e ex-diretora permite cogitar um clima de rivalidade pairando no ambiente escolar, motivado, talvez, pela diversidade socioeconômica dos alunos das duas escolas: "O João Pinheiro sempre teve a nata [da sociedade], e nós ficávamos com o resto", disse ela. Ainda assim, quando o grupo escolar Ildefonso Mascarenhas se estabeleceu, de vez, em um prédio próprio,

[...] uns [alunos] saíram do João Pinheiro e vieram, porque a tia ia lecionar, não sei quem ia lecionar. Então, nós juntamos um pouco, arrastamos um pouco do João Pinheiro. Mas o resto era aluno pobre mesmo, eles alimentavam lá com a gente. (MOUKACHAR, 2009, entrevista). dona Nagib:

A situação de desconforto teve um ápice, como se lê nesta passagem do relato de

Eu já estava na direção. E a dona Carmelita, que era inspetora, a delegada de Ensino - vou falar nos termos antigos -, ela veio e fechou o gabinete e falou: "Nagib, eu te dou um mês para você sair, senão eu vou acabar com o Mascarenhas, eu vou fechar a escola!". "Dona Carmelita, para onde que eu vou?".

A ambiguidade na responsabilidade pela administração (resolução dos problemas) se mostra nessa passagem do relato de dona Nagib: se o poder de escolha do corpo docente cabia ao chefe de gabinete e ao prefeito, o poder de "acabar" com a escola estava na inspetoria educacional. Por outro lado, resolver o problema da falta de espaço físico era tarefa da direção escolar, como sugerem as palavras de dona Nagib: 
Chamei [...] a dona Clorinda Junqueira [que era] muito sensata, uma mulher de valor [...], chamei a Maria Lúcia, as professoras mais antigas [e disse]: "Gente, é pra sair, tá despejando nós. Como é que nós vamos fazer?". Então vamos sair, procurar casa e procuramos. Aquela casa onde é o sapateiro, "tivemos lá. [...] Sapataria do Capitão. Olhamos e tal... "Não, não dá!" Procuramos até uma casa de mulheres lá em cima, 'tava desocupada, na [rua] 25 [...]. Fomos lá, tinha uns quartinhos - "Gente, também não dá!". Aí a diretora do João Pinheiro, a dona Jandira, falou: eu vou arrumar pra vocês a casa que era do meu sogro, na [rua] 21, uma casa antiga.

Não seria incorreto supor que a tensão resultante do funcionamento de dois grupos escolares no mesmo prédio fosse desconhecida das autoridades educacionais nem que o estado e prefeitura se excluíam da resolução de problemas estruturais da educação; tampouco que a ação do poder público fosse além da criação legal da escola: publicar um decreto, realizar uma solenidade de formalização. Fazer a escola funcionar estruturalmente era problema cuja solução cabia a quem pertencia ao cotidiano escolar.

Dona Nagib aponta outros fatos que indiciam o "descaso" do estado com as condições de funcionamento das escolas:

Eu fui a Belo Horizonte umas cinco vezes, eu e a vice-diretora, mais uma outra [pessoa]. A prefeitura mandava a gente com o doutor Eurípedes Melo, que era o engenheiro na prefeitura. Nós vamos com ele. Naquele tempo, a gente ganhava prédio na CARPE [Comissão de Construção e Reconstrução de Prédios Públicos de Minas Gerais];14 é aonde a gente ia pedir prédio lá em Belo Horizonte; a gente ía na CARPE, pedia, explicava que estávamos sendo despejados, mas como é que faz? Foi um prédio feito de tanto as professoras amolarem, de [tanto] irem em Belo Horizonte, voltar e pedir. Aí nos deram o prédio. (Grifos nossos).

A ação de pedir para ganhar sugere que a obtenção de instalações físicas para uma escola do estado era uma questão de representação política; prova disso pode ser a presença de um engenheiro da prefeitura, que daria mais credibilidade e legitimidade à demanda. De tanto "amolarem", conseguiram o que queriam: em 7 de novembro de 1977, a atual Escola Estadual Professor Ildefonso Mascarenhas da Silva de $1^{\circ}$ grau teve erguida sua sede. Mas ainda com incertezas sobre a responsabilidade administrativa, isto é, sobre o ônus de erguer um prédio e ampliá-lo: “[...] o terreno quem nos deu foi o Acácio Cintra, que era o prefeito. [...] [então] começou a batalha pra ganhar o prédio. E ganhamos [...] [Depois] Fizemos mais quatro salas: duas em cima, duas em baixo, pra poder ter o direito de colocar a quinta série pra frente".

Como se vê, mais que da ação dos governos estadual e municipal, foram a luta e determinação de pessoas da comunidade intraescolar que resultaram na construção e ampliação do prédio do grupo escolar Ildefonso Mascarenhas. Para a comunidade escolar, sobretudo a quem se esforçou para consolidar a independência do grupo escolar, a sede materializava a luta pelo acesso à educação, assim como criava uma referência espacial ao corpo docente e discente: um sentimento de pertença a um lugar que anulava a sensação de que "[...] o João Pinheiro não era a nossa casa [...]" (MOUKACHAR, 2009, entrevista). Essa conquista, porém, não apagou a lentidão da expansão escolar no município - "O Mascarenhas já tinha 30 anos quando nós ganhamos o prédio, entendeu?" - nem a precariedade — "Quando chovia, [...] não tinha forro, não" (MOUKACHAR, 2009, entrevista). Ainda assim, um prédio próprio abriu espaço a um número maior de discentes, 
e isso mostrou que a sociedade confiava no grupo escolar Ildefonso Mascarenhas como espaço para educar formalmente.

\section{Sopa, saber e sevícias}

O relato de dona Nagib - como vimos — dá pistas das circunstâncias de criação e do funcionamento do grupo escolar Ildefonso Mascarenhas; também revela traços do perfil socioeconômico dos alunos que o frequentaram nos primeiros anos de funcionamento. Tal perfil ganha mais contornos no relato do ex-aluno Walter Arantes Guimarães (2011, entrevista). Segundo ele, “[...] naquela época, os 'meninos da caixa' eram os meninos mais pobres. [...] quando nois estudava, era tudo misturado: os pobres e os ricos, até a quarta série. Depois cada um ia para outra escola que quisesse".

Com efeito, a mistura dos alunos se exemplifica na alimentação servida na escola: "[...] eu me recordo bem dessa sopa... Era um mingau para os pobres — os 'meninos da caixa', que [era como se] falava naquela época; mas, no final, dava para todo mundo a sopa: rico e pobre. Todo mundo comia" (GUIMARÃES, 2011, entrevista). Essa passagem do relato sugere que não só a aprendizagem escolar motivava a frequência, mas também a oportunidade de comer; mais que isso, reitera a ideia de inacessibilidade à educação particular referida há pouco, porque deixa entrever que o grosso da população não tinha condições de suprir nem sequer necessidades mais básicas que escolarização.

Por outro lado, o preparo da sopa que alimentava os alunos de condições financeiras precárias converge para o que diz Fischer (2000) sobre o papel que se atribuía aos professores dos anos 50 veiculado por revistas cujo conteúdo tratava da educação. Em sua análise da Revista do Ensino publicada no Rio Grande do Sul, ela notou que,

Ao longo das páginas folheadas, vai se explicitando a professora, "mestre humilde e ignorada", que tem uma missão a cumprir aqui na terra: "salvar almas para Deus e formar cidadãos para a Pátria" (RE, set./1959, p. 15). Ou seja, mestras são pessoas "sempre prontas para a íngreme escalada do dever e a busca suprema dos bens eternos" (RE, set./1959, p. 15). Por isso, a professora é "mãe espiritual", e por isso "ensinar é mais que criar a carne, é criar a alma", fazendo com que os alunos sejam "o grande amor de sua vida". Magistério é vocação e a professora jamais é identificada como uma profissional. Seu trabalho não supõe recompensa "neste mundo". Os méritos são computados "pela glória de tudo dar e pelo triunfo de nada receber" (RE, set./1958, p. 2). (FISCHER, 2000, p. 3)

Como disse o entrevistado Walter Guimarães, embora a sopa se destinasse aos alunos pobres, a escola não impedia os demais de comer: todos tinham direito a ela. Isso deixa transparecer uma escola orientada a não discriminar seus alunos entre si, isto é, a igualá-los em seu interior, talvez por causa de uma eventual discriminação experimentada no período em que o grupo escolar Ildefonso Mascarenhas funcionou no prédio de outro grupo escolar, o João Pinheiro.

Mesmo a possibilidade de estudar (quando havia duas escolas públicas para uma população urbana superior a $10 \mathrm{mil}$ habitantes) e se alimentar não estimulava a frequência, pois esta pressupunha associar aprendizagem com castigo e constrangimento.

Todos os alunos riam de nois, pois tinha um menino [...] que ele sabia tudo. Eu morria de raiva dele. Ele acertava tudo que a professora perguntava. Então ela punha ele para bater na gente; ele ficava só 
esperando, com a palmatória na mão, até cuspia nela pra dor ser maior. Eu morria de raiva dele. Mas tinha que ser assim: se errasse, apanhava! Isso os meninos pequenos, [n]os maiores a professora batia com a régua.

Sabe-se que o castigo físico - a violência - como forma de punição permeou as relações sociais quase naturalmente; por exemplo, as relações entre senhor e escravo, pais e filhos. E a atitude de castigar, de punir partia de quem ocupava o topo de uma hierarquia dual: de quem manda sobre quem obedece; de quem ocupa uma posição de autoridade em tais relações. Mais que isso, o castigo se destinava a corrigir comportamentos, a disciplinar, a educar até. Na relação entre professor e aluno, o uso do castigo físico, segundo Veiga (2003, p. 501) remonta — para não recuarmos demais no passado — ao século XVII, às congregações lassalistas (fundadas por São João Batista de La Salle), que viam a "[...] correção dos atos como um meio pedagógico importante para manter a ordem em sala de aula". A prática perdeu força no século XIX do ponto de vista legal: a Lei Imperial de 1827 proibiu o uso de castigos físicos nas escolas, em detrimento do castigo moral; assim, o sentimento de medo daria lugar ao de vergonha (SÁ; SIQUEIRA, 2006), pois o castigo não se coadunava com uma sociedade que se pretendia civilizada e desenvolvida.

Dito isso, no caso do grupo escolar Mascarenhas, segundo o relato do entrevistado, a hierarquia supostamente dual em que ocorria o castigo previa um terceiro elemento: o aluno mais avançado no quesito aprendizagem; se isso configurava certa autoridade perante os demais alunos, ele ainda se encontrava numa posição de subordinação, pois tinha de cumprir ordem dada pela professora. Além disso, o uso de dois instrumentos para alunos de faixa etária diferente condensava práticas distintas geograficamente; segundo Luckesi (1998, p. 133), enquanto no Sul era comum o professor bater com a "[...] a régua escolar no aluno que não respondesse com adequação às suas perguntas sobre uma lição qualquer" [no Nordeste] esta mesma prática era efetivada por meio da palmatória".

Curiosamente, a passagem do relato sugere que o castigo era praticado não para disciplinar comportamentos ou manter a ordem na sala de aula; mas para punir o fracasso de aprendizagem: o erro; a não apreensão de "[...] um conjunto determinado de conhecimentos, uma seqüência metodológica ou coisa assemelhada" (LUCKESI, 1998, p. 135). Essa prática didático-pedagógica — afirma Luckesi (1998, p. 134) — revela uma face mais grave da ação pedagógica porque a professora não estaria interessada "[...] em descobrir quem sabe o que foi ensinado, mas sim quem não aprendeu, para poder expor publicamente aos colegas a sua fragilidade"; ainda segundo esse autor, a vergonha de não saber deveria servir, "[...] de um lado, de lição para o aluno que não aprendeu e, de outro, de exemplo para os colegas, na medida em que ficam sabendo o que lhes pode acontecer no caso de não saberem a lição quando forem indagados" (LUCKESI, 1998, p. 134).

Enfim, se a intenção do castigo desferido por um aluno supostamente mais adiantado do ponto de vista da aprendizagem era ter efeito moral nos discentes, também suscitava sentimentos como a raiva: um alimento para o revide, a violência. Mas é provável que a vergonha, o constrangimento, o sentimento de "incapacidade", de "inferioridade" etc. que tal situação pudesse suscitar tenham tido impacto negativo e traumatizante na vida escolar dos alunos castigados. Isso porque o entrevistado Guimarães, após concluir o quarto ano primário, não quis continuar os estudos prestando o exame de admissão para ingressar no ginásio; preferiu trabalhar na lavoura para ajudar o pai a manter a família.

Por outro lado, naquele momento, continuar os estudos era ação não coadunável com os paradigmas de uma sociedade que valorizava pouco a educação formal (a capacidade de ler, escrever e calcular); do contrário, o número de escolas públicas 
certamente seria maior nos anos 40. Como a economia era fundada na atividade agropecuária, as possibilidades de produção laboral convergiam para o trabalho no campo, que independia da formação escolar; do contrário, o contingente rural não seria majoritariamente analfabeto no município nos anos 40 e 50.

Ainda assim, a capacidade de ler, escrever e calcular deve ter impactado positivamente na vida profissional do entrevistado, que se elegeu vereador por dois mandatos. Mais que isso, para ele, a leitura, em especial de livros sobre religião, ameniza os efeitos da solidão (ele mora sozinho, pois os filhos, casados, moram longe); igualmente, a capacidade e o hábito de escrever mantêm viva sua memória, pois ele tem feito anotações que pretende reunir em um livro.

\section{Educação, economia e política em Ituiutaba: alguns questionamentos}

Posto isso, se for provável que a escolarização em Ituiutaba em meados do século passado tenha sido importante para introduzir seus alunos, por exemplo, do mundo da política, não se pode dizer que a política tenha sido forte o suficiente para ampliar o número de escolas no mundo dos alunos. Tampouco se pode dizer que uma economia ascendente tenha sido capaz de fortalecer a força política no município.

Com efeito, a lacuna de 37 anos entre a criação do primeiro grupo escolar e a do segundo oferece margem para questionar o porquê de um período tão longo sem que outras escolas públicas fossem criadas. Ora, Ituiutaba teve projeção suficiente para fazer funcionar um grupo escolar já em 1910, quando sua economia representava pouco ou nada relativamente ao prestígio da oligarquia fazendeira na política mineira (também na política nacional); afinal, a elite política mudaria sua feição cafeeira para industrial só a partir dos anos 20, quando o processo de industrialização se impôs. Além disso, a história da educação no país tem mostrado que a expansão dos grupos escolares foi estimulada pelo governo federal a partir dos anos 30 para alfabetizar maciçamente. Assim, parece ser quase natural que o município ampliasse o quadro de escolas públicas naquele período. Eis por que convém investigar noutros estudos as razões do desprestígio orligárquico-político para que o município ficasse mais de três décadas com uma escola pública, enquanto sua população se ampliava com a migração. Seria por que a população era majoritariamente rural? Mas uma cidade cogitada para ser capital federal não merecia ostentar índices educacionais elevados?

Por outro lado, na década de criação do segundo grupo escolar, Ituiutaba gozava de uma projeção econômica estadual que, talvez, pudesse prestigiar sua força política para demandar ao estado a criação de mais escolas públicas no município. Ora, em 1948 foi implantado um "Plano de recuperação econômica e de fomento da produção" de que talvez Ituiutaba prescindisse, dada a força de sua rizicultura como motor da economia; força econômica que contrastava com a do próprio estrado; afinal, este demandou a implementação de tal plano. Se for provável esse contraste, então cabe questionar por que, em tal cenário de pujança econômica, o analfabetismo era também pujante? Seria por que a riqueza gerada pela produção de grãos replicava a tradição de concentração de renda nas mãos de poucos; de uma elite capaz de estimular a criação e manutenção de tantas escolas particulares no período em que a educação pública - a população pobre, analfabeta ficou esquecida?

Seja como for, não há dúvida de que houve mediação política para criar o segundo grupo escolar de Ituiutaba, sobretudo do Poder Executivo. Mas sua criação valeu, especialmente, da ação de um professor atuante no Rio de Janeiro "[...] chamado então pra 
ser Secretário da Educação" (PAIVA, 2009, entrevista), sensível às demandas educacionais de Ituiutaba que, provavelmente, seu oficial de gabinete lhe descreveu.

\section{Considerações finais}

Esta problematização da gênese do grupo escolar Ildefonso Mascarenhas busca oferecer subsídios para escrever uma história-problema da educação no país, sobretudo da expansão da escola pública no século passado pela difusão de um modelo de escola - o grupo escolar - ao qual subjazia o desejo de massificar a alfabetização como projeto republicano em prol do progresso nacional. No interior, cuja feição demográfica mudava graças ao aumento da população urbana, massificar o ensino podia concretizar um projeto de unidade e homogeneidade. E isso dependia de políticas públicas.

Contudo, como resultado de tais políticas, o funcionamento desse grupo escolar em seus primeiros anos permite por em xeque a consistência, abrangência e completude delas. Ora, a criação da escola foi marcada por situações que apontam certa precariedade na expansão educacional: instalações improvisadas, administração dividida em três instâncias (estado, município e escola), relações políticas pouco claras para cessão de terrenos e construção de prédios, critérios nem profissionais nem pedagógicos para escolher a composição do corpo docente, práticas de sala de aula ainda fundadas em preceitos de uma pedagogia que prevê o castigo, dentre outros.

Num contexto de condições tais, não causa espanto a escola levar quase duas para se equilibrar e se consolidar estruturalmente como instituição educacional útil e eficaz. Ainda assim, em seus primórdios, cumpriu papel central ao oferecer escolarização mínima a uma população que não dispunha de outra opção, mesmo que a oferta educacional a crianças de até 7 anos de idade não garantisse mudanças estruturais em suas condições de vida. Afinal, tais mudanças dependiam de outras instâncias como um mercado de trabalho que oferecesse aos pais emprego sólido e bem-remunerado, de modo que pudessem prescindir da mão de obra dos filhos em idade escolar para ajudar a manter a família em condições mínimas de dignidade social.

\section{Referências}

ARAUJO, José C. S. Os grupos escolares em Minas Gerais como expressão de uma política pública: uma perspectiva histórica. In: VIDAL, Diana G. (Org.). Grupos escolares: cultura escolar primária e escolarização da infância no Brasil (1893-1971). Campinas: Mercado de Letras, 2006.

FARIA FILHO, Luciano Mendes de. Dos pardieiros aos palácios: forma e cultura escolares em Belo Horizonte (1906/1918). 1996. Tese (Doutorado em Educação) Faculdade de Filosofia, Letras e Ciências Humanas, Universidade de São Paulo.

FERREIRA, Ana Emília Cordeiro Souto; CARVALHO, Carlos Henrique. O Grupo Escolar João Pinheiro: sua gênese e desenvolvimento no cenário histórico-educacional de Ituiutaba (1908-1988). In: RIBEIRO, Betânia Oliveira Laterza; SOUZA, Sauloéber Társio (Org.). Do público ao privado, do confessional ao laico: a história das instituições escolares na Ituiutaba do século XX. Uberlândia: ed. UFU, 2009, p. 73-115.

FISCHER, Beatriz Daudt. Imprensa pedagógica como dispositivo de subjetivação da professora moderna: estudo de caso a partir da Revista do Ensino no Brasil/1950-1970. Linhas, Florianópolis: UDESC, v. 5, n. 1, s. p., 2004. 
GONÇALVES NETO, Wenceslau; GATTI JÚNIOR, Décio. Reflexões em torno da expansão escolar no Triangulo Mineiro. Boletim do CDHIS - Centro de Documentação e Pesquisa em História, Uberlândia, v. 11, n. 22, p. 5-7, 1998.

LUCKESI, Cipriano Carlos. Prática Escolar: do Erro Como Fonte de Castigo ao Erro Como Fonte de Virtude. Série Idéias, São Paulo: FDE, n. 8, p. 133-140, 1998.

MORAES, Vera C. O. Tudo pela pátria: a história do Instituto Marden (1933-45). 2004. Dissertação (Mestrado em Educação) — Faculdade de Educação da Universidade Federal de Uberlândia, Uberlândia.

MOURA SOBRINHO, Vicente Batista de; INÁCIO FILHO, Geraldo. Imprensa e massificação do ensino em Uberlândia, MG: preliminares do percurso histórico (19401960). Cadernos de História da Educação, Uberlândia: ed. UFU, v. 1, n. 1, p. 127-32, jan./dez. 2002. Disponível em:

<http://www.seer.ufu.br/index.php/che/article/viewFile/320/313>. Acesso em: 8 ago. 2013.

RIBEIRO, Betânia Oliveira Laterza; SILVA, Elizabeth Farias. O Grupo Escolar de Villa Platina e a educação: variações intrínsecas sobre um prédio determinado. In: RIBEIRO, Betânia Oliveira Laterza; SOUZA, Sauloéber Társio (Org.). Do público ao privado, do confessional ao laico: a história das instituições escolares na Ituiutaba do século XX. Uberlândia: ed. UFU, 2009, p. 47-72.

RIBEIRO, Betânia Oliveira Laterza. Escolarização pública na região de Ituiutaba/MG (1940-50). Projeto de pesquisa aprovado pelo Conselho Nacional de Pesquisa para ser desenvolvido no curso de Pedagogia da Faculdade de Ciências Integradas do Pontal. Ituiutaba, MG, 2010.

RIBEIRO, Betânia Oliveira Laterza; SILVA, Elizabeth Farias. Educação e domínio: escola como ilusão de inclusão social do "negro" no Brasil da década de 1930. Cadernos de História da Educação, Uberlândia: ed. UFU, v. 9, n. 2, p. 363-75, jul./dez. 2010.

SÁ, Nicanor Palhares; SIQUEIRA, Elizabeth Madureira. Modernidade e castigos escolares: oscilando entre os costumes e a legislação (o caso da Província de Mato Grosso). In: LOMBARDI, José Claudinei; SAVIANI, Dermeval; NASCIMENTO, Maria Isabel (Org.). Navegando pela história da educação Brasileira. 1. ed. Graf. FE:

HISTEDBR, v. 1, p. 1-14, 2006. Disponível em: <http://www.histedbr.fae.unicamp.br/ navegando/artigos_frames/artigo_086.html>. Acesso em: 8 maio 2013.

SAVIANI, Dermeval. O legado educacional do século XX no Brasil. São Paulo: Autores Associados, 2004.

SILVA, Dalva Maria Oliveira. Memória: lembrança e esquecimento. Trabalhadores nordestinos no Pontal do Triângulo Mineiro nas décadas de 1950 e 1960. 1997.

Dissertação (Mestrado em História) — Programa de Estudos Pós-graduados em História, Pontifícia Universidade Católica de São Paulo.

SOUZA, Rosa Fátima de. Templos de civilização. A implantação da escola primária graduada no Estado de São Paulo (1890-1910). São Paulo: ed. UNESP, 1998.

SOUZA, Rosa Fátima de. Lições da escola primária. In: SAVIANI, Dermeval et al. $O$ legado educacional do século XX no Brasil. Campinas: Autores Associados, 2004.

SOUZA, Sauloéber Tarsio de. O universo escolar nas páginas da imprensa tijucana (Ituiutaba/MG — anos de 1950 e 1960). Cadernos de História da Educação, v. 9, n. 2, p. 523-41, jul./dez. 2010, 
VEIGA, Cynthia Greive. Sentimentos de vergonha e embaraço: novos procedimentos disciplinares no processo de escolarização da infância em Minas Gerais no século XIX. In: CONGRESSO DE HISTÓRIA DA EDUCAÇÃO DE MINAS GERAIS, 2., 2003, Uberlândia. Anais... Uberlândia: Universidade Federal de Uberlândia, 2003. Disponível em: <http://www.faced.ufu.br/nephe/images/arq-ind-ome/eixo7/completos/sentimentosvergonha.pdf $>$. Acesso em: 8 maio 2012.

VILELA, Claudia Oliveira Cury. Escola Noturna "Machado de Assis": primeira instituição municipal de ensino primário noturno da cidade de Ituiutaba, MG (1941-1960). 2011. 141 f. Dissertação (Mestrado em Educação) — Faculdade de EducaçãoUniversidade federal de Uberlândia, Ufberlândia.

- Fonte documental

BRASIL. Congresso Nacional. Mensagem do presidente da República Eurico Gaspar Dutra dirigida ao Congresso Nacional em 1949. Rio de Janeiro: 1949. Disponível em: <http://www.crl.edu/brazil/presidential>. Acesso em: 15 nov. 2010.

\section{- Fontes orais}

PAIVA, Hélio Benicio de. Ituiutaba, MG, 30 jan. 2009. 1 fita cassete (60 min.). Entrevista concedida a nós.

MOUKACHAR, Nagib Bitar. Ituiutaba, MG, 4 fev. 2009. 1 fita cassete (60 min.). Entrevista concedida a nós.

GUIMARÃES, Walter Arantes. Ituiutaba, MG, 8 jan. 2011.1 fita cassete (60 min.). Entrevista concedida a nós.

- Fontes jornalísticas

FOLHA DE ITUIUTABA. Ituiutaba, MG, 14 set., ano VII, n. 28, 1947.

Recebido em novembro-12

Aprovado em maio-13

Notas

\footnotetext{
${ }^{1}$ Este estudo compôs a pesquisa mais ampla Modernização e Educação Pública no interior do Brasil: estudo de caso no Triângulo Mineiro (1940-1960), aprovado para o edital Demanda Universal, processo APQ00892 (anuênio 2008-9).

${ }^{2}$ Betânia de Oliveira Laterza Ribeiro é docente do curso de Pedagogia da Faculdade de Ciências Integradas do Pontal (FACIP) e da pós-graduação da Faculdade de Educação (FACED), ambas da Universidade Federal de Uberlândia; é pós-doutora pela Universidade de São Paulo (USP), campus de Ribeirão Preto, e doutora pela USP de São Paulo.

${ }^{3}$ Valéria Aparecida de Lima é coordenadora pedagógica Escola Especial Bem-Me-Quer, de Ituiutaba, MG; é graduada em Pedagogia pela FACIP/UFU e especializada em História e Cultura Brasileira.

${ }^{4}$ Armindo Quillici Neto é docente do curso de Pedagogia da FACIP e da pós-graduação da FACED; é doutor em Educação pela Universidade Estadual de Campinas.

${ }^{5}$ O Grupo Escolar João Pinheiro foi criado em 23 de dezembro de 1908, como Grupo Escolar de Villa Platina, mas começou suas atividades letivas em 1910. Em 18 de maio de 1952, um incêndio destruiu a
} 
biblioteca, o assoalho e teto do pavilhão central, com isso a escola ficou inativa por mais de um ano; mesmo após a construção do prédio próprio se manteve fechado por falta de mobiliário. Essa inatividade prejudicou muitas crianças, pois o Ildefonso Mascarenhas era insuficiente para suprir a demanda. Parte da história do grupo escolar historia do João Pinheiro foi escrita por Ribeiro e Silva (2009) e Ferreira e Carvalho (2009).

${ }^{6}$ Convém esclarecer que, entre a criação do Grupo Escolar João Pinheiro e a do Ildefonso Mascarenhas, surgiu outra escola pública, cuja biografia é peculiar: em parte, porque foi criada pela comunidade negra em seus primórdios para suprir a demanda dessa parcela da população; em parte, porque a prefeitura assumiu sua administração e manutenção posteriormente. Sua formalização legal ocorreu em 4 de maio de 1937, quando a lei 13 criou a Escola Municipal Noturna 13 de Maio. O decreto-lei 73, de 25 de novembro de 1941, mudou o nome para Escola Municipal Machado de Assis; com a mudança de nome, veio a mudança de prédio: a escola foi transferida para as instalações do Grupo Escolar João Pinheiro. Como escola 13 de Maio, essa instituição foi objeto de artigo de Ribeiro e Silva (2010); como escola Machado de Assis, foi objeto da dissertação de mestrado de Cury (2011).

${ }^{7}$ Sobre o fluxo migratório de estados nordestinos para o Pontal do Triângulo Mineiro, ver Silva (1997).

${ }^{8}$ Eis o texto da notícia: "Conforme vimos anunciando, Ituiutaba tem sido freqüentemente visitada pelas subcomissões encarregadas da localização do futuro Distrito Federal. Todos os técnicos e os estudiosos que nos visitam não escondem o entusiasmo. Há grandes possibilidades que a região que circunda nosso município, venha a ser brindada com a preferência da comissão pró localização da capital, para a sede do governo federal. Há dias esteve entre nós o professor da Universidade de Sourbone, na França, Dr. Francis Ruellan, chefiando uma caravana de estudiosos. O ilustre visitante enalteceu a região como das mais ricas, e por delicadeza de sua parte, nos foi oferecido o mapa [...] que representa a região B, estando no mesmo incluída grande parte do município de Ituiutaba. Oferecemos, pois à curiosidade de nossos leitores, em primeira mão, o único mapa até hoje publicado em que focaliza uma das regiões em estudo, para a localização da capital da República. Esteve, na semana findada, entre nós, mais uma comissão de geógrafos do Conselho Nacional de Geografia chefiada do Dr. Fábio Macedo Soares Guimarães, uma das figuras brilhantes que vem emprestando a grande responsabilidade da escolha da capital, todo o seu talento e dinamismo. Fazem parte ainda desta Comissão os Drs. Orlando Valverde, José Veríssimo e o nosso conterrâneo Speridião Faissol. Aos nossos visitantes desejamos felicidades na grande missão que lhes está confiada”.

${ }^{9}$ Sobre a expansão escolar em Minas, ver, por exemplo, Gonçalves Neto e Gatti Júnior (1998), sobre o Triângulo Mineiro.

${ }^{10} \mathrm{O}$ decréscimo populacional entre as décadas de 60 e 70 decorreu da emancipação política de alguns distritos administrados pelo município de Ituiutaba. Ainda assim, o movimento de urbanização é bastante evidenciado (cf. censos demográficos dos anos 40 a 70).

${ }^{11}$ Mineiro, Ildefonso Mascarenhas da Silva foi advogado magistrado, professor e escritor. Nasceu em 6 de setembro de 1904, em Tabuleiro Grande, distrito de Sete Lagoas, hoje município de Paraopeba; morreu no Rio de Janeiro, em 25 de julho de 1969. Começou seus estudos básicos no Colégio Arnaldo, em Belo Horizonte, e prosseguiu no Instituto Lafayette, Rio de Janeiro; iniciou seus superiores na Universidade do Brasil, onde se graduou em Direito, e doutorou-se em Direito Privado na Universidade de Minas Gerais; também era doutor em Arquitetura e Ciências Econômica. Lecionou no Colégio Pedro II, Rio de Janeiro, e em faculdades de Direito, Filosofia e Ciências Econômicas. Foi advogado-geral de Minas Gerais e juiz do Tribunal Superior Eleitoral; em 21 de setembro de 1946, assumiu o cargo de secretário Estadual de Educação e Saúde Pública, no qual ficou ate 19 e março de 1947, a convite do interventor Alcides Lins.

${ }^{12}$ Eis o texto da mensagem manuscrita: "Comunico [que] você foi nomeado oficial do gabinete do seu velho professor, abraços" (grifo nosso).

${ }^{13}$ Normalista formada pela Escola Marden, aos 17 anos de idade, Nagib Bitar Moukachar fez concurso em Belo Horizonte (MG), em 1947, para ser professora de Ginástica; após ser nomeada, voltou a Ituiutaba, para inaugurar o Grupo Escola Ildefonso Mascarenhas. Assumiu essa disciplina e lecionou por dez anos; também foi professora regente antes de tornar vice-diretora e, em 1957, diretora, cargo que ocupou até os anos 80, quando se aposentou.

${ }^{14}$ Extinta em 1987, pela lei 9.524 . 